\title{
A comparative study of sevoflurane induction using continuous tidal volume breaths versus three vital capacity breaths technique in adult patients undergoing elective surgical procedures under general anaesthesia
}

\author{
Yogesh Kumar Manik ${ }^{1}$, Vipin Kumar Dhama ${ }^{2, *}$, Subhash $^{3}$, Navab $\operatorname{Singh}^{4}$, Sudhir Kumar ${ }^{5}$ \\ ${ }^{1,2}$ Associate Professor, ${ }^{3}$ Professor, ${ }^{4}$ Assistant Professor, ${ }^{5}$ Resident, Dept. of Anaesthesiology, Lala Lajpat Rai Memorial Medical \\ College, Meerut, Uttar Pradesh, India \\ *Corresponding Author: \\ Email: drvipindhama@yahoo.com
}

Received: $27^{\text {th }}$ July, 2017

Accepted: $06^{\text {th }}$ December, 2017

\begin{abstract}
Introduction: Previous studies have shown stable cardiovascular parameters and minimal airway irritation with sevoflurane induction in adults. Also, time taken for induction is comparable to intravenous drugs. The authors planned to conduct a randomized, control study to compare the effect of continuous tidal volume breaths versus three vital capacity breaths for sevoflurane induction on time taken for induction, haemodynamic parameters and intubating conditions in adult patients undergoing elective surgery under general anaesthesia.

Materials and Methods: Sixty patients planned to undergo elective surgical procedures under general anaesthesia were included in study. Patients were divided randomly using sealed opaque envelope method in group 1 and group 2 of thirty patients each. Group 1 patients received continuous tidal volume breath and group 2 patients received three vital capacity breaths. The statistical analysis was done using IBM SPSS Statistics Software Version 15.0. The independent samples Student $t$-test was used to determine the differences in basic clinical characteristics, mean Arterial Pressure, heart Rate, and intubation time between the two groups. Quantitative data were evaluated by chi square test. Any p value less than 0.05 was considered as significant.

Result: Variation in heart rate between two groups was statistically significant at 1 min. $(p=0.04), 2$ min. $(p=0.01)$ and 3 min. $(\mathrm{p}=0.004)$ after start of induction. The time taken for loss of consciousness was significantly less in vital capacity induction group. ( $\mathrm{p}<0.001$ ) Intubating conditions were better in group2 (optimal, good in $90 \%$ and $10 \%$ participants respectively) as compared to group1 (optimal, good in $76.67 \%$ and $23.33 \%$ participants respectively).

Conclusion: Heart rate and mean arterial pressure remain stable during sevoflurane induction in adult patients using three vital capacity breath or tidal volume breath technique. Intubating conditions are better and time taken to lose consciousness is less with vital capacity breaths.
\end{abstract}

Keywords: Sevoflurane, Adult, Tidal volume, Vital capacity.

\section{Introduction}

Sevoflurane is a non irritant volatile anaesthetic having a pleasant odor, blood: gas solubility coefficient of 0.69 , minimal haemodynamic effects, rapid elimination. ${ }^{1-3}$ Sevoflurane has been used for induction of anaesthesia due to these properties. Studies have shown that time to loss of lid reflex after starting of sevoflurane induction is similar to intravenous induction. ${ }^{4}$ Vital capacity or tidal breathing induction can be used for inhalation induction of anesthesia with sevoflurane. The authors planned to conduct a randomized, control study to compare the effect of continuous tidal volume breaths versus three vital capacity breaths for sevoflurane induction on time taken for induction, haemodynamic parameters and intubating conditions in adult patients undergoing elective surgery under general anaesthesia.

\section{Materials and Methods}

After approval from the ethics committee of the institution, the present study was conducted on patients admitted in SVBP Hospital, affiliated to L.L.R.M Medical College Meerut during march 2016 to march
2017. A thorough pre-anaesthetic check-up (PAC) was done. A written and informed consent was obtained from the participants. Inclusion criteria were adult patient of ASA grade I and II, BMI (body mass index) range between 20-25 undergoing elective abdominal surgeries. Patients having any major systemic illness were excluded from the study. Patients having anticipated difficult airway on PAC were also not included.

The patients were kept fasting for six hours for solid and liquid prior to surgery. Tablet Alprazolam $0.25 \mathrm{mg}$ and Ranitidine $150 \mathrm{mg}$ were taken by patient the night before surgery.

For group allocation, thirty slips with group1 written on them and thirty slips with group 2 written were prepared and put inside an envelope. An anaesthetist not involved in study took one slip from envelope before every procedure and patient group was decided.

After shifting the patient to Operation theatre, the breathing technique was explained again and patient performed the breathing maneuveres. Multipara 
monitor (Infinity vista XL, Drager) was attached and reading of heart rate (HR), systolic blood pressure (SBP), diastolic blood pressure (DBP), mean arterial pressure (MAP), blood oxygen saturation levels $\left(\mathrm{SPO}_{2}\right)$ as baseline values were recorded. Patient was preloaded with $5 \mathrm{ml} / \mathrm{kg}$ body weight of Lactate ringer's solution. All patients were premedicated with injection fentanyl $1 \mathrm{mcg} / \mathrm{kg}$, injection glycopyrrolate $0.005 \mathrm{mg} / \mathrm{kg}$, injection ranitidine $50 \mathrm{mg}$ and injection ondansetron $4 \mathrm{mg}$ intravenously 10 minutes before induction. The gas flow (anaesthesia workstation-Drager fabius plus) was set at $3 \mathrm{~L} / \mathrm{min}$ nitrous oxide and $2 \mathrm{~L} / \mathrm{min}$ oxygen and the sevoflurane vaporizer (Vapor 2000 Drager) was advanced upto $8 \%$ setting. Closed circuit was primed for half minute with this gas mixture. Patients in group 1 maintained their resting tidal volume and respiratory rate while breathing incrementally increasing concentrations of sevoflurane (sevorane, Abbott pharmaceuticals ltd.), beginning with $1.5 \%$ in the nitrous oxide-oxygen mixture. The vaporizer concentration was increased by $1.5 \%$ every third to fourth breath until the dial setting on the calibrated vaporizer reached $8 \%$.

In group 2, after forced expiration (to residual volume) patient took three vital capacity breaths of gas mixture. In all patients, when eye lash reflex was absent, guedel airway of appropriate size was placed and controlled ventilation was done (to maintain $\mathrm{EtCO}_{2}$ between 25 and $30 \mathrm{mmHg}$ ) and five minutes after the first breath of gas mixture, laryngoscopy and intubation were attempted. A single investigator performed anaesthesia induction.

Patient movement were defined as any movement of the body. Time taken to tracheal intubation was defined as the period between mouth opening for laryngoscopy and putting the ETT across the vocal cords in the trachea under direct vision using Macintosh blade. No verbal response was considered as loss of consciousness. $^{5} \quad$ Spontaneous respiration was considered if visible chest rise was present after removing face mask for intubation.

Intubating conditions were defined as per below table 1 .

Table 1: Definitions of intubating condition ${ }^{6}$

\begin{tabular}{|l|l|}
\hline $\begin{array}{c}\text { Intubating } \\
\text { condition }\end{array}$ & \multicolumn{1}{|c|}{ Definition } \\
\hline Optimal & $\begin{array}{l}\text { jaw relaxed ,open vocal cords, no coughing at } \\
\text { tracheal intubation }\end{array}$ \\
\hline Good & $\begin{array}{l}\text { jaw partially relaxed and/or intermittent coughing } \\
\text { after tracheal intubation }\end{array}$ \\
\hline Marginal & $\begin{array}{l}\text { jaw moderately stiff and/or continuous coughing } \\
\text { after tracheal intubation }\end{array}$ \\
\hline Poor & Jaw severely stiff and/or vocal cords were closed \\
\hline
\end{tabular}

Other monitored parameters were: 1) heart rate, blood pressure every minute till 10 minutes; 2) time to loss of consciousness 3) time taken for tracheal intubation. Hypotension was defined as mean arterial blood pressure $<60$ $\mathrm{mmHg}$. Bradycardia was defined as heart rate $<60 / \mathrm{min}$. Hypoxemia was defined as $\mathrm{SpO}_{2}<90 \%$.

The statistical analysis was done using IBM SPSS Statistics Software Version 15.0. The independent samples Student $t$-test was used to determine the differences in basic clinical characteristics, mean Arterial Pressure, heart Rate and intubation time between the two groups. Quantitative data were evaluated by chi square test. Any $\mathrm{p}$ value less than 0.05 was considered as significant. The Qualitative data are represented in number (\%) and mean \pm standard deviation (SD).

Table 2: Patient characteristics

\begin{tabular}{|l|c|c|c|c|}
\hline & Group I (n=30) & Group II $(\mathbf{n}=\mathbf{3 0})$ & t value & p value \\
\hline $\begin{array}{l}\text { Age in years } \\
(\text { Mean } \pm \text { SD) }\end{array}$ & $35.73 \pm 13.96$ & $34.1 \pm 11.56$ & 0.49 & 0.62 \\
\hline BMI $\left(\mathrm{Kg} / \mathrm{m}^{2}\right)$ & $20.13 \pm 1.52$ & $19.66 \pm 1.56$ & 1.17 & 0.25 \\
\hline $\begin{array}{l}\text { ASA I(number of } \\
\text { patients) }\end{array}$ & 27 & 26 & & \\
\hline $\begin{array}{l}\text { ASA II(number } \\
\text { of patients) }\end{array}$ & 3 & 4 & & \\
\hline
\end{tabular}

Table 3: Comparison in heart rate changes at different time intervals between two groups

\begin{tabular}{|l|c|c|c|c|}
\hline Heart Rate (per min.) & Group1(n=30) & Group2(n=30) & t value & p value \\
\hline \multicolumn{1}{|c|}{ Time interval } & $83.06 \pm 9.16$ & $87.36 \pm 8.06$ & -1.93 & 0.06 \\
\hline base line & $91.2 \pm 12.45$ & $95.9 \pm 11.83$ & -1.49 & 0.14 \\
\hline 1 min. Before induction &
\end{tabular}




\begin{tabular}{|l|c|c|c|c|}
\hline 1 min. After induction & $92.23 \pm 15.47$ & $100.6 \pm 14.68$ & -2.15 & 0.04 \\
\hline 2 min. After induction & $89.43 \pm 14.89$ & $99.63 \pm 14.6$ & -2.68 & 0.01 \\
\hline 3 min. After induction & $87.03 \pm 13.09$ & $96.9 \pm 12.39$ & -2.30 & 0.004 \\
\hline 4 min. After induction & $92.36 \pm 13.08$ & $98.73 \pm 17.63$ & -1.59 & 0.12 \\
\hline 5 min. After induction & $101.2 \pm 13.93$ & $99.5 \pm 13.85$ & 0.47 & 0.68 \\
\hline 7 min. After induction & $97.93 \pm 14.08$ & $102.66 \pm 11.17$ & -1.44 & 0.15 \\
\hline 10 min. After induction & $92.36 \pm 14.93$ & $95.63 \pm 12.38$ & -0.92 & 0.36 \\
\hline
\end{tabular}

Table 4: Comparison in mean arterial pressure (MAP) changes at different time intervals between two groups

\begin{tabular}{|l|c|c|c|c|}
\hline MAP (mm Hg.) & Group1 & Group2 & t value & p value \\
\hline \multicolumn{1}{|c|}{ Time interval } & $85.53 \pm 12.68$ & $89.2 \pm 9.88$ & -1.25 & 0.22 \\
\hline Base line & $98.13 \pm 10.46$ & $101.2 \pm 11.01$ & -1.10 & 0.27 \\
\hline 1 min.Before induction & $95.33 \pm 8.63$ & $97.2 \pm 10.67$ & -0.74 & 0.46 \\
\hline 1 min. After induction & $86.6 \pm 12.87$ & $86.83 \pm 11.46$ & -0.07 & 0.94 \\
\hline 2 min. After induction & $82.6 \pm 12.73$ & $85.13 \pm 17.61$ & -0.64 & 0.53 \\
\hline 3 min. After induction & $81.53 \pm 12.32$ & $87.06 \pm 16.66$ & -1.46 & 0.15 \\
\hline 4 min. After induction & $82.13 \pm 15.98$ & $82.33 \pm 17.4$ & -0.45 & 0.96 \\
\hline 5 min. After induction & $92.87 \pm 14.77$ & $88.83 \pm 12.24$ & 1.15 & 0.25 \\
\hline 7 min. After induction & $91.57 \pm 10.94$ & $91.17 \pm 9.9$ & 0.15 & 0.88 \\
\hline 10 min. After induction & 91.57 & & \\
\hline
\end{tabular}

Table 5: Comparison of complication outcomes between the two study groups

\begin{tabular}{|l|c|c|c|c|}
\hline \multicolumn{2}{|l}{ Complications during induction } \\
\hline Coughing & Group 1 (n=30) & Group 2 (n=30) & $x^{2}$ value & P value \\
\hline Laryngospasm & 0 & 0 & 0 & 1 \\
\hline Breathholding & 0 & 0 & 0 & 1 \\
\hline $\begin{array}{l}\text { Body } \\
\text { Movements }\end{array}$ & 0 & 0 & 0 & 1 \\
\hline Secretions & 0 & 0 & 0 & 1 \\
\hline $\begin{array}{l}\text { Spontaneous } \\
\text { respirations }\end{array}$ & $3(10 \%)$ & $1(3.33 \%)$ & 1.07 & 0.3 \\
\hline
\end{tabular}

Table 6: Comparison of intubating conditions between the two study groups

\begin{tabular}{|c|c|c|c|c|}
\hline \multicolumn{5}{|c|}{ Intubating condition } \\
\hline & Group $1(n=30)$ & Group $2(n=30)$ & $\chi^{2}$ value & P value \\
\hline Optimal & $23(76.67 \%)$ & $27(90 \%)$ & \multirow{4}{*}{1.92} & \multirow{4}{*}{0.17} \\
\hline Good & $7(23.33 \%)$ & $3(10 \%)$ & & \\
\hline Marginal & 0 & 0 & & \\
\hline Poor & 0 & 0 & & \\
\hline
\end{tabular}

\section{Result}

Both the groups were statistically comparable in context of age, body mass index, ASA status (Table 2). Variation in heart rate between two groups was statistically significant at $1 \mathrm{~min} . \quad(\mathrm{p}=0.04), 2$ $\min .(\mathrm{p}=0.01)$ and $3 \mathrm{~min} . \quad(\mathrm{p}=0.004)$ after start of induction (table 3). No statistically significant difference is seen in MAP parameters of both the groups(table 4) .Time to loss of consciousness was $54.47 \pm 13.35$ seconds in group 1 and $37.83 \pm 7.83$ seconds in group $2(\mathrm{p}<0.001)$.

The incidence of spontaneous respiration was more in case of tidal volume breath group $(10 \%)$ in comparison to the vital capacity group $(3.33 \%)$ but the difference is not statistically significant $(\mathrm{p}>0.05)$.

Intubating conditions were better in group2 with optimal and good condition in $90 \%$ and $10 \%$ participants respectively as compared to group 1 with optimal and good condition in $76.67 \%$ and $23.33 \%$ participants respectively (table6).

\section{Discussion}

Using sevoflurane as an induction agent in adult patients is associated with clinically insignificant changes in heart rate, mean arterial pressure and minimal adverse effects (coughing, laryngospasm) on respiratory system. Vital capacity breath induction 
results in better intubating conditions than tidal volume induction.

Lin TC demonstrated that sevoflurane can be safely used as an induction agent in patients undergoing gynaecological surgery. ${ }^{8}$ McClelland stated that in obstetric patients volatile anaesthetic induction can be used in place of intravenous induction. ${ }^{9}$ Kirkbride DA et al observed that sevoflurane induction in elderly patients is well tolerated and mean arterial pressure is maintained. $^{10}$

In our study difference in heart rate between two groups was statistically significant at $1 \mathrm{~min}$., $2 \mathrm{~min}$. and 3 min. after start of induction. Patient might not be taking full vital capacity breaths so sevoflurane alveolar concentration could have been less resulting in increase in heart rate. C. Lejus et al observed that the inhibition of parasympathetic fibres to heart by sevoflurane may cause transitory tachycardia. ${ }^{11} \mathrm{M}$. Yurino et al observed that heart rate was stable with vital capacity breathing but increased significantly with tidal breathing. Also, systolic and diastolic blood pressure decreased but stayed within clinically safe levels. ${ }^{12}$

Hernán $\mathrm{R}$ observed a slight hypertensive and tachycardic response to intubation when using $5 \%$ sevoflurane. $^{13}$ In our study we also observed that sevoflurane doesn't cause clinically significant haemodynamic changes (heart rate, mean arterial pressure) during induction.

Time to loss of consciousness was less than 60 seconds in patients taking vital capacity breaths (group 2 ). This might be because of rapidly achieved alveolar concentration of sevoflurane in these patients. ElRadaideh KM observed that loss of consciousness was produced in approximately 51 seconds using $8 \%$ sevoflurane as induction agent. ${ }^{14}$ Martín Larrauri R et al observed that the time to loss of eyelash reflex was $68 \pm$ 7 seconds. ${ }^{15}$ In clinical practise, the time difference is not of much importance as loss of consciousness (absent verbal response) may not mean optimum intubating conditions.

Incidence of spontaneous respiration (clinical observation of chest rise) was more with tidal volume breath $(10 \%)$ as compared to the vital capacity breath $(3.33 \%)$. The difference observed might be due to larger alveolar concentration achieved and more deeper plane of anaesthesia with vital capacity breath as compared to the tidal volume breath. Boonmak $\mathrm{P}$ observed that high initial concentration of sevoflurane results in high incidence of apnea. ${ }^{16}$ El-Radaideh KM observed no apnea during use of $8 \%$ sevoflurane for induction. Ti LK observed prolonged jaw tightness when sevoflurane was used as induction agent in comparison to propofol. ${ }^{17}$ However, they observed no difficulty in intubation once jaw was opened. Muzi M et al observed that breath holding occurred in $15 \%$ of volunteers breathing sevoflurane/oxygen and occurred in only $7.5 \%$ of those breathing sevoflurane/nitrous oxide. $^{18}$
Limitations of our study were a small sample size, inclusion of only non pregnant adult patients undergoing elective surgery. We did not monitor the bispectral values during the experiment and thus, could not assess the anesthetic depth of patients.

\section{Conclusion}

Sevoflurane can be safely administered for induction purpose in adult patients using both the three vital capacity breath as well as conventional tidal volume breath technique.

\section{References}

1. Fredman B, Nathanson MH. Sevoflurane for outpatient anaesthesia: a comparison with propofol. Anesth Analg. 1995;81:823-8.

2. Smith I, Nathanson M, White PF. Sevoflurane-a long awaited volatile anaesthetic. Br J Anaesth.1996;76:43545.

3. Djaiani GN, Hall JE, Pugh S. Vital Capacity inhalational induction with sevoflurane: an alternative to standard intravenous induction for patients undergoing cardiac surgery. Journal of Cardiothoracic and Vascular Anesthesia 2001;15:169-74.

4. Philip BK, Lombard LL, Roaf ER, Drager LR. Comparison of vital capacity induction with sevoflurane to intravenous induction with propofol for adult ambulatory anesthesia. Anesth Analg. 1999;89(3):623-7.

5. M. P. Drage, J. Nunez, R. S. Vaughan .Jaw thrusting as a clinical test to assess the adequate depth of anaesthesia for insertion of the laryngeal mask. Anaesthesia, 1996;51,1167-7.

6. Aqil M, Haq A ,Amjad Rasheed, Rana Altaf . Effect of two different doses of fentanyl on intubating conditions with sevoflurane inhalation without neuromuscular blocking agents in adults. Anaesth Pain \& Intensive Care 2009;13(2);52-6.

7. Mangat PS, Jones JG. Perioperative hypoxaemia. In: Kaufman L (ed.) Anaesthesia Review 10. Edinburgh: Churchill Livingstone, 1993:83-106.

8. Lin TC, Lu CC, Kuo CK, Hsu CH. Single vital-capacity and successive tidal-volume breathing of sevoflurane in induction of anesthesia for tracheal intubation in gynecologic patients. Acta Anaesthesiol Taiwan.2008;46(2):66-70.

9. McClelland S. H. , Hardman J. G. Inhalational induction of anaesthesia in adults: time for a breath of fresh air? Anaesthesia, 2007 62:1087-9.

10. Kirkbride DA, Parker JL, Williams GD, Buggy DJ. Induction of anesthesia in the elderly ambulatory patient: a double-blinded comparison of propofol and sevoflurane. Anesth Analg . 2001;93(5):1185-7.

11. Lejus, C., Bazin, V., Fernandez, M., Nguyen, J. M., Radosevic. Inhalation induction using sevoflurane in children: the single-breath vital capacity technique compared to the tidal volume technique.Anaesthesia, (2006),61:535-40.

12. Yurino M, Kimura H. Induction of anesthesia with sevoflurane, nitrous oxide, and oxygen: A comparison of spontaneous ventilation and vital capacity rapid inhalation induction (VCRII) techniques. Anesth Analg 1993;76,598-601.

13. Hernán R Muñoz, Julio A González . Hemodynamic response to tracheal intubation after vital capacity rapid inhalation induction (VCRII) with different 
concentrations of sevoflurane. Journal of clinical anaesthesia. 1999. 11(7),567-71.

14. El-Radaideh KM, Al-Ghazo MA. Single breath vital capacity induction of anesthesia with $8 \%$ sevoflurane versus intravenous propofol for laryngeal tube insertion in adults. Saudi Med J.2007;28(1):36-40.

15. Martín-Larrauri R, Gilsanz F, Rodrigo J, Vila P, Ledesma $\mathrm{M}$. Conventional stepwise vs. vital capacity rapid inhalation induction at two concentrations of sevoflurane. Eur J Anaesthesiology. 2004;21(4):265-71.

16. Boonmak P, Boonmak S, Pattanittum P. High initial concentration versus low initial concentration sevoflurane for inhalational induction of anaesthesia. Cochrane Database Syst Rev.2012 12;(9):CD006837.

17. Ti LK, Chow MY, Lee TL .Comparison of sevoflurane with propofol for laryngeal mask airway insertion in adults. Anesth Analg.1999;88(4):908-12.

18. Muzi M, Robinson BJ . Induction of anesthesia and tracheal intubation with sevoflurane in adults. Anesthesiology. 1996;85(3):536-43. 